\title{
Role of mast cell- and non-mast cell-derived inflammatory mediators in immunologic induction of synaptic plasticity
}

A.A.C. Albuquerque ${ }^{1}$, J.H. Leal-Cardoso ${ }^{2}$ and D. Weinreich ${ }^{3}$

\author{
1Departamento de Fisiologia e Farmacologia, Centro de Ciências da Saúde, \\ Universidade Federal do Ceará, 60430-270 Fortaleza, CE, Brasil \\ 2Departamento de Ciências Fisiológicas, Centro de Ciências da Saúde, \\ Fundação Universidade Estadual do Ceará, 60740-000 Fortaleza, CE, Brasil \\ ${ }^{3}$ Department of Pharmacology and Experimental Therapeutics, School of Medicine, \\ University of Maryland at Baltimore, Baltimore, MD 21201, USA
}

\section{Correspondence \\ A.A.C. Albuquerque \\ Departamento de Fisiologia e \\ Farmacologia, CCS, UFC \\ Rua Cel. Nunes de Melo, 1127 \\ 60430-270 Fortaleza, CE \\ Brasil \\ Fax: 55 (085) 243-9333}

Presented at the XI Annual Meeting of the Federação de Sociedades de Biologia Experimental, Caxambu, MG, Brasil, August 21-24, 1996.

Research supported by CAPES, CNPq and NIH (No. NS 22069).

Received April 11, 1996 Accepted June 2, 1997

\begin{abstract}
We have previously discovered a long-lasting enhancement of synaptic transmission in mammal autonomic ganglia caused by immunological activation of ganglionic mast cells. Subsequent to mast cell activation, lipid and peptide mediators are released which may modulate synaptic function. In this study we determined whether some mast cell-derived mediators, prostaglandin $\mathrm{D}_{2}\left(\mathrm{PGD}_{2} ; 1.0 \mu \mathrm{M}\right)$, platelet aggregating factor (PAF; $0.3 \mu \mathrm{M}$ ) and $\mathrm{U} 44619$ (a thromboxane analogue; $1.0 \mu \mathrm{M})$, and also endothelin-1 (ET-1; $0.5 \mu \mathrm{M})$ induce synaptic potentiation in the guinea pig superior cervical ganglion (SCG), and compared their effects on synaptic transmission with those induced by a sensitizing antigen, ovalbumin (OVA; $10 \mu \mathrm{g} / \mathrm{ml})$. The experiments were carried out on SCGs isolated from adult male guinea pigs (200$250 \mathrm{~g}$ ) actively sensitized to OVA, maintained in oxygenated Locke solution at $37^{\circ} \mathrm{C}$. Synaptic potentiation was measured through alterations of the integral of the post-ganglionic compound action potential (CAP). All agents tested caused long-term (LTP; duration $\geq 30 \mathrm{~min}$ ) or short-term (STP; $<30 \mathrm{~min}$ ) potentiation of synaptic efficacy, as measured by the increase in the integral of the post-ganglionic CAP. The magnitude of mediator-induced potentiation was never the same as the antigen-induced long-term potentiation (A-LTP). The agent that best mimicked the antigen was $\mathrm{PGD}_{2}$, which induced a $75 \%$ increase in CAP integral for LTP (antigen: 94\%) and a 34\% increase for STP (antigen: 91\%). PAF-, U44619-, and ET-1-induced increases in CAP integral ranged for LTP from 34 to $47 \%$, and for STP from 0 to $26 \%$. These results suggest that the agents investigated may participate in the induction of A-LTP.
\end{abstract}

Key words

- Prostaglandin $\mathrm{D}_{2}$

- Platelet aggregating factor

- Endothelin-1

- Thromboxane

- Mast cell

- Synaptic plasticity 
Presynaptic stimulation can cause conspicuous changes in the synaptic efficacy of chemical synaptic transmission which can last from seconds to hours. An increase in synaptic efficacy is called short-term potentiation (STP) or long-term potentiation (LTP) if it persists for a few minutes, or many minutes to hours, respectively (1). LTP is thought to be strongly related to the mechanism of memory and pain (2-4).

It has been demonstrated that antigen-antibody-mediated activation of resident mast cells in the superior cervical ganglion (SCG) causes an increase in the efficacy of synaptic transmission which, in most cases, is long lasting (>30 min) and has been termed antigen-induced long-term potentiation (A-LTP) $(5,6)$. Histamine, which is released from mast cells in the guinea pig SCG upon antigen challenge, has been shown to have a stimulatory (through $\mathrm{H}_{1}$ receptors) action on ganglionic nicotinic transmission (7), but causes only a short-lasting $(<10 \mathrm{~min})$ potentiation of synaptic efficacy (8). Catecholamines (which can be released from sympathetic cell bodies) and serotonin (found in mast and enterochromaffin cells) can potentiate ganglionic synaptic transmission $(9,10)$. Since blockade of $\alpha$ - and $\beta$-adrenergic, muscarinic and nicotinic cholinergic, and serotoninergic receptors did not block ALTP, we investigated whether other substances released by mast cell activation can induce LTP. We examined three derivatives of arachidonic acid, prostaglandin $\mathrm{D}_{2}\left(\mathrm{PGD}_{2}\right)$, platelet aggregating factor (PAF) and U44619 (a thromboxane analogue), as well as endothelin-1 (ET1). All compounds were shown to induce LTP, although not to the same extent as A-LTP.

The experiments were carried out on adult male guinea pigs (200-250 g) actively sensitized to ovalbumin (OVA; chicken egg albumin, Sigma Chemical Co., St. Louis, MO), as described previously (5). Briefly, animals were injected intraperitoneally with ovalbu$\min (10 \mathrm{mg} / \mathrm{kg})$ at two-day intervals for 6 days. Twenty-one to 45 days after the last injection, the animals were killed and the
SCG, along with their pre- and postganglionic nerve trunks, were dissected and immediately submerged in cold $\left(5^{\circ} \mathrm{C}\right)$ Locke solution with the following composition: 136 $\mathrm{mM} \mathrm{NaCl}, 5.6 \mathrm{mM} \mathrm{KCl}, 14.3 \mathrm{mM} \mathrm{NaHCO}_{3}$, $1.2 \mathrm{mM} \mathrm{NaH}_{2} \mathrm{PO}_{4}, 2.2 \mathrm{mM} \mathrm{CaCl}_{2}, 1.2 \mathrm{mM}$ $\mathrm{MgCl}_{2}, 11 \mathrm{mM}$ dextrose, and $0.03 \mathrm{mM}$ choline chloride, bubbled continuously with $95 \%$ $\mathrm{O}_{2}-5 \% \mathrm{CO}_{2}, \mathrm{pH} 7.2$ to 7.4.

SCG were trimmed of excess connective tissue and pinned to the Sylgard (Dow Corning, Midland, MI) coated floor of a recording chamber ( $\cong 0.25 \mathrm{ml}$ volume). Ganglia were superfused $(3-5 \mathrm{ml} / \mathrm{min})$ at $36-37^{\circ} \mathrm{C}$ with oxygenated Locke solution. Unless otherwise stated, agonists were superfused over ganglia for $5 \mathrm{~min}$.

Evoked compound action potentials (CAP) were routinely recorded with extracellular suction electrodes placed 2-4 mm distant from the ganglion at the level of the superior nerve branch, and connected to the preamplifier (0.1-1 kHz; WPI, Sarasota, FL). Stimulation was carried out with suction electrodes placed 3-10 mm away from the ganglion at the level of the cervical sympathetic nerve trunk (CST). The effect of application of an antigen or reagent on ganglionic synaptic transmission was assessed by measuring changes in the integral of the evoked CAP. CAP were evoked and collected via pCLAMP software (Axon Instruments, Foster City, CA) running on an IBM PC XT with a TL1 interface (Axon Instruments). The computer was connected to a Dell System 320 (20 MHz, 386 PC) via a two-node local area network (Lantastic Artisoft Inc., Tucson, AZ) for the purpose of monitoring the peak-to-peak amplitude and integral CAP responses "on-line". The monitoring/analysis program ("CAP", written in collaboration with BME Systems Inc., Baltimore, MD) run on the Dell 320 system permitted analysis of the responses during the experiment.

Postganglionic CAP were usually evoked at a frequency of $0.2 \mathrm{~Hz}$, and the control CAP integral was usually adjusted to values close to 
$50 \%$ of the maximum attainable either by adjusting preganglionic stimulus intensity or by adding hexamethonium $(100-300 \mu \mathrm{M})$ to the Locke solution and stimulating the CST supramaximally. Potentiation of synaptic transmission was considered to be long-term if it lasted $\geq 30 \mathrm{~min}$, and STP for periods of time $<30 \mathrm{~min}$.

All salts were analytical grade and were purchased from Sigma Chemical Company. ET-1, PAF, PGD 2 , and U44619 were kindly donated by Dr. B. Undem, Johns Hopkins University.

Data are reported as mean \pm SEM and were considered to be significant at $\mathrm{P}<0.05$.

The effects of the arachidonic acid derivatives PAF and $\mathrm{PGD}_{2}$, of the thromboxane analogue U44619, and of the cytokine ET-1 are shown in Table 1. Also shown for comparison are the effects produced by the antigen OVA (Figure 1). Five ganglia from sensitized and 7 from non-sensitized guinea pigs were exposed to bovine serum albumin $(10 \mu \mathrm{g} / \mathrm{ml})$ and OVA $(10 \mu \mathrm{g} / \mathrm{ml})$ (sensitizing antigen), respectively. No alteration of synaptic transmission $(>5 \%)$ was observed. Unsensitizing antigen, therefore, never induced synaptic potentiation.

Column 2 in Table 1 shows the quantification of induction of long-term potentiation, reported as the increase in CAP integral and ratio of occurrence (given in parentheses) of LTP. All four substances induced LTP, as recorded in at least $25 \%$ preparations tested. The magnitude of CAP potentiation produced by PAF, U44619 or ET-1 was 50\% that induced by antigen (94\%) and, taking values of all three agents together, differed significantly from the values for sensitizing antigen $(\mathrm{P}<0.05$, ANOVA and the Scheffé test). The incidence of LTP was higher with U44619 but lower with PAF and ET-1 when compared with A-LTP (34 of 60 trials). PGD $_{2}$ caused an increase in CAP (75\%) that was not statistically different from potentiation produced by the antigen. Interestingly, $\mathrm{PGD}_{2}$ induced LTP with nearly the same incidence as OVA.
Table 1 - Effect of sensitizing antigen, platelet aggregating factor (PAF), U44619, prostaglandin $\mathrm{D}_{2}\left(\mathrm{PGD}_{2}\right)$, and endothelin-1 (ET-1) on the efficacy of synaptic transmission in guinea pig superior cervical ganglion (SCG).

a Mean potentiation lasting $\geq 30$ min (LTP); potentiation lasting $<30$ min (STP). bMean increase in compound action potential (CAP) integral reported as percentage of control integral \pm SEM. For the statistical significance of differences between means, see text. CAP integrals ( $\mathrm{mV} . \mathrm{ms}$ ) in preparations exposed to sensitizing antigen and $\mathrm{PGD}_{2}$ were $17.76 \pm 1.67(N=60)$ and $13.24 \pm 1.96(N=14)$, respectively, and $31.81 \pm 2.34$ and $21.27 \pm 2.39$, in the presence of these agents. CNumber of increases with a

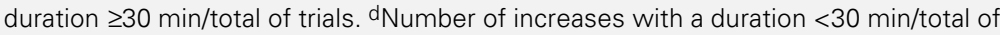
trials.

\begin{tabular}{lccc}
\hline Agent & $\begin{array}{c}\text { Increase in CAP } \\
\text { integral in LTPa }\end{array}$ & $\begin{array}{c}\text { Increase in CAP } \\
\text { integral in STPa }\end{array}$ & $\begin{array}{c}\text { No change in synaptic } \\
\text { transmission }\end{array}$ \\
\hline Sensitizing antigen & $94 \pm 8.1^{\mathrm{b}}$ & $91 \pm 11.9$ & - \\
& $(34 / 60)^{\mathrm{c}}$ & $(26 / 60)^{\mathrm{d}}$ & $(0 / 60)$ \\
PAF $(0.3 \mu \mathrm{M})$ & $47 \pm 13.7$ & $24 \pm 9.4$ & - \\
& $(5 / 16)$ & $(6 / 16)$ & $(5 / 16)$ \\
U44619 $(1.0 \mu \mathrm{M})$ & $34 \pm 6.8$ & - & - \\
PGD $2(1.0 \mu \mathrm{M})$ & $(3 / 4)$ & $(0 / 4)$ & $(1 / 4)$ \\
& $75 \pm 19.1$ & $34 \pm 13.9$ & - \\
ET-1 $(0.5 \mu \mathrm{M})$ & $(7 / 15)$ & $(5 / 15)$ & - \\
& $42 \pm 12.7$ & $26 \pm 5.5$ & $(1 / 12)$
\end{tabular}

The third column in Table 1 shows the inflammatory mediators that induced STP with ratios of occurrence that were either higher (ET-1) or lower (PAF and $\mathrm{PGD}_{2}$ ) than that produced by the antigen (26/60). The average magnitude of potentiation was significantly smaller $(0-34 \%)$ than that induced by the antigen $(\mathrm{P}<0.05$, ANOVA and the Scheffé test). The fourth column shows the ratio of occurrence when there was no potentiation of synaptic transmission.

The major finding of the present study is that some mast cell mediators induce shortand long-term synaptic potentiation in the isolated superior cervical ganglion of the guinea pig. Two types of control experiments reported in previous studies $(6,8)$ have shown that these synaptic potentiations are not attributable to artifacts, such as alterations of extracellular series and shunt resistances. Firstly, sensitizing antigen and histamine, although inducing an increase in postsynaptic CAP integral, did not affect the presynaptic CAP. Secondly, CAP evoked by 
Figure 1 - Antigen- and prostaglandin $\mathrm{D}_{2}\left(\mathrm{PGD}_{2}\right)$-induced longterm potentiation in the superior cervical ganglion in vitro. Representative course of variation of the compound action potential (CAP) integral (mV.ms; ordinate) recorded before, during (5 $\mathrm{min})$ and after ganglionic exposure to a sensitizing antigen (ovalbumin (OVA); $10 \mu \mathrm{g} / \mathrm{ml}$ ) in $A$ or to $\mathrm{PGD}_{2}$ $(1.0 \mu \mathrm{M})$ in $\mathrm{B}$. The arrow indicates the time when the challenge started. Insets on top of each panel: actual CAP voltage recordings under control (a) and experimental (b) conditions during exposure to OVA (panel $A$ ) or to $\mathrm{PGD}_{2}$ (panel $B$ ) and after wash (c). Each data point represents the average magnitude of the integral of 12 postganglionic CAPs evoked at $0.2 \mathrm{~Hz}$. Calibration: $1 \mathrm{mV}, 10 \mathrm{~ms}$.
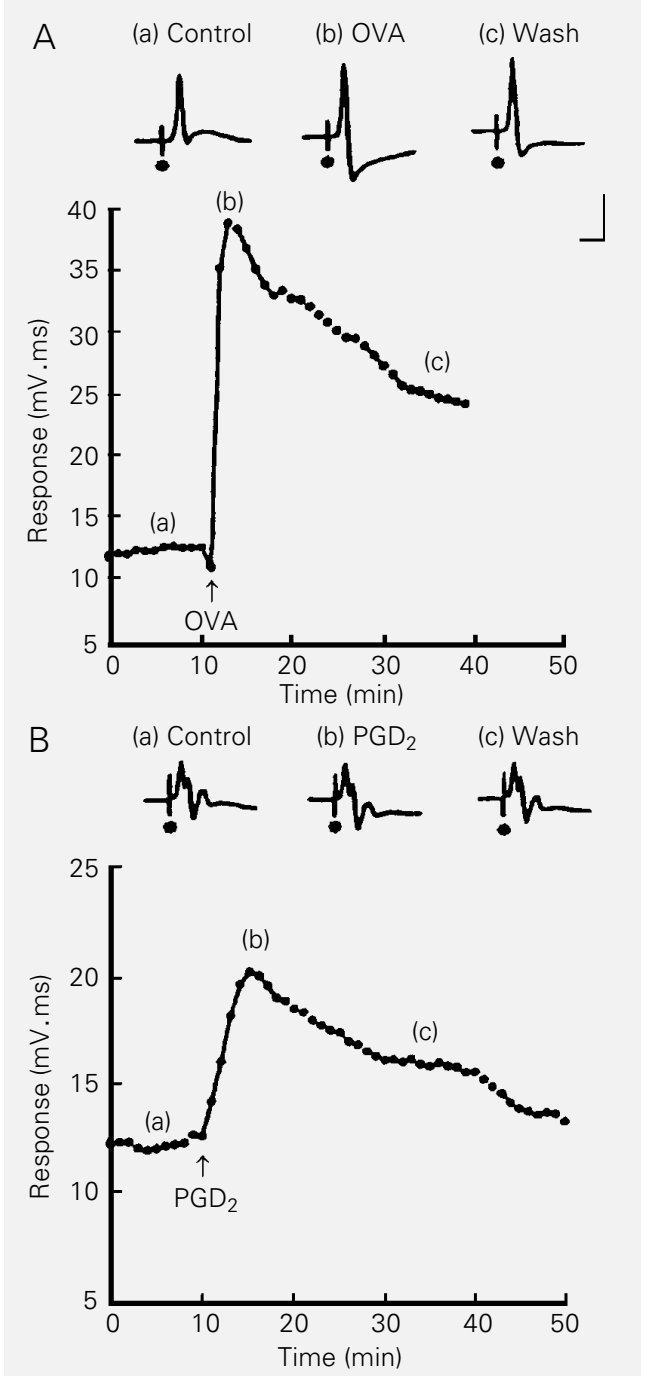

direct ganglion stimulation in the presence of hexamethonium $(1-5 \mu \mathrm{M})$ was not affected by either antigen or histamine. Previous investigations have revealed that histamine, an important mediator released from mast cells, can potentiate ganglionic synaptic transmission in guinea pig ganglia. However, this biogenic amine has been convincingly shown not to participate in A-LTP (8). We also observed that preincubation of SCG with indomethacin did not interfere with the induction of A-LTP. Thus, the mast cell mediator(s) responsible for A-LTP remain uncharacterized. The robust LTP produced by exogenously applied $\mathrm{PGD}_{2}$, a known mast cell-derived lipid mediator, suggests that the involvement of these prostanoids in A-LTP should be reassessed. PAF is also released from mast cells upon antigenic stimulation.

ET-1, though not a known mast cellderived mediator, may be formed in autonomic ganglia following antigenic stimulation of resident mast cells. Although this cytokine could induce STP and LTP in the guinea pig SCG, the infrequent occurrence of LTP produced by ET-1 makes it unlikely that this peptide plays a major role in A-LTP. However, various mediators may perhaps undergo synergistic interaction and thus significantly contribute to A-LTP.

\section{References}

1. Bliss TVP \& Lomo T (1973). Long-lasting potentiation of synaptic transmission in the dentate area of anaesthetized rabbits following stimulation of the perforant path. Journal of Physiology, 232: 331-356.

2. Chung SH (1977). Synaptic memory in the hippocampus. Nature, 266: 677-678.

3. Teyler TJ \& Discenna P (1984). Long-term potentiation as a candidate mnemonic device. Brain Research Review, 7: 15-28.

4. Hawkins RD, Kandel ER \& Siegelbaum SA (1993). Learning to modulate transmitter release: themes and variations in synaptic plasticity. Annual Review in Neuroscience, 16: 625-665.
5. Weinreich D \& Undem BJ (1987). Immunological regulation of synaptic transmission in isolated guinea pig autonomic ganglia. Journal of Clinical Investigation, 79: 1529-1532.

6. Weinreich D, Undem BJ \& Leal-Cardoso JH (1992). Functional effects of mast cell activation in sympathetic ganglia. Annals of the New York Academy of Sciences, 664: 293-308.

7. Christian EP \& Weinreich D (1992). Presynaptic histamine $\mathrm{H} 1$ and $\mathrm{H} 2$ receptors modulate sympathetic ganglionic synaptic transmission in the guinea pig. Journal of Physiology, 457: 407-430.
8. Weinreich D, Undem BJ, Taylor G \& Barry MF (1995). Antigen-induced long-term potentiation of nicotinic synaptic transmission in the superior cervical ganglion of the guinea pig. Journal of Neurophysiology, 73: 2004-2016.

9. Trendelenburg $U$ (1956). The action of 5hydroxytryptamine on the nictitating membrane and on the superior cervical ganglion of the cat. British Journal of Pharmacology, 11: 74-80.

10. Briggs CA, McAfee DA \& McCaman RE (1988). Long-term regulation of synaptic acetylcholine release and nicotinic transmission: the role of cyclic AMP. British Journal of Pharmacology, 93: 399-411. 